\title{
A circularly polarized array antenna with inclined patches using both-sided MIC technology
}

\author{
Muhammad Asad Rahman ${ }^{1 a)}$, Eisuke Nishiyama ${ }^{1}$, \\ Md. Azad Hossain ${ }^{2}$, Quazi Delwar Hossain ${ }^{2}$, and Ichihiko Toyoda ${ }^{1}$ \\ ${ }^{1}$ Graduate School of Science and Engineering, Saga University, \\ 1 Honjo-machi, Saga 840-8502, Japan \\ ${ }^{2}$ Faculty of Electrical and Computer Engineering, Chittagong University of \\ Engineering and Technology, Chittagong-4349, Bangladesh \\ a)asad31@ceng.ec.saga-u.ac.jp
}

\begin{abstract}
A $2 \times 2$ circularly polarized array antenna for X-band applications is proposed in this letter. A new technique is employed to attain circular polarization by means of linear polarization patches. Two orthogonal modes with quadrature phase shift is achieved by making two patches quarter wavelength ahead and orthogonal with respect to other two patches. The feed network of the array is designed using both-sided MIC technology to overcome the impedance matching problem of conventional feed networks. A 3-dB axial ratio bandwidth of $1.41 \%$ is obtained and antenna gain is around $6.36 \mathrm{dBic}$.
\end{abstract}

Keywords: microstrip antenna, circular polarization, array antenna, bothsided MIC technology

Classification: Antennas and Propagation

\section{References}

[1] B. Y. Toh, R. Cahill, and V. F. Fusco, "Understanding and measuring circular polarization," IEEE Trans. Educ., vol. 46, no. 3, pp. 313-318, Aug. 2003. DOI:10.1109/TE.2003.813519

[2] K. F. Lee and K. F. Tong, "Microstrip patch antennas - basic characteristics and some recent advances," Proc. IEEE, vol. 100, no. 7, pp. 2169-2180, Feb. 2012. DOI:10.1109/JPROC.2012.2183829

[3] P. Bhartia, I. Bahl, R. Garg, and A. Ittipiboon, Microstrip Antenna Design Handbook, Artech House, London, 2001.

[4] C. Y. Huang and K. L. Wong, "Coplanar waveguide-fed circularly polarized microstrip antenna," IEEE Trans. Antennas Propag., vol. 48, no. 2, pp. 328 329, Feb. 2000. DOI:10.1109/8.833083

[5] A. K. Gautam, A. Kunwar, and B. K. Kanaujia, "Circularly polarized arrowhead-shape slotted microstrip antenna," IEEE Antennas Wireless Propag. Lett., vol. 13, pp. 471-474, Mar. 2014. DOI:10.1109/LAWP.2014.2309719

[6] Y. Ushijima, E. Nishiyama, and M. Aikawa, "Single-layer integrated microstrip array antenna for dual circular polarisation," IET Microw. Antennas Propag., vol. 6 , no. 8, pp. 962-968, Jun. 2012. DOI:10.1049/iet-map.2011.0413 
[7] M. A. Rahman, Q. D. Hossain, M. A. Hossain, and P. Chowdhury, "Design of a circular polarization array antenna with dual-orthogonal feed circuit," Proc. Int Conf. of Informatics, Electronics \& Vision (ICIEV2014), Dhaka, Bangladesh, pp. 1-5, May 2014. DOI:10.1109/ICIEV.2014.6850754

[8] J. Huang, "A technique for an array to generate circular polarization with linearly polarized elements," IEEE Trans. Antennas Propag., vol. 34, no. 9, pp. 1113-1124, Sep. 1986. DOI:10.1109/TAP.1986.1143953

[9] M. N. Jazi and M. N. Azarmanesh, "Design and implementation of circularly polarised microstrip antenna array using a new serial feed sequentially rotated technique," IEE Proc., Microw. Antennas Propag., vol. 153, no. 2, pp. 133140, Apr. 2006. DOI:10.1049/ip-map:20050005

[10] J. Xu, M. Wang, H. K. Huang, and W. Wu, "Circularly polarized patch array fed by slotted waveguide," IEEE Antennas Wireless Propag. Lett., vol. 14, pp. 8-11, Sep. 2014. DOI:10.1109/LAWP.2014.2354072

[11] M. A. Rahman, E. Nishiyama, M. A. Hossain, Q. D. Hossain, and I. Toyoda, "Experimental investigation of a circularly polarized array antenna with inclined linear polarization patches," Proc. 2016 IEICE General Conf., Kyushu, Japan, B-1-186, Mar. 2016.

[12] M. Aikawa and H. Ogawa, "Double-sided MICs and their applications," IEEE Trans. Microw. Theory Techn., vol. 37, no. 2, pp. 406-413, Feb. 1989. DOI:10.1109/22.20068

[13] M. A. Rahman, Q. D. Hossain, M. A. Hossain, E. Nishiyama, and I. Toyoda, "Design and parametric analysis of a planar array antenna for circular polarization," Int. J. Microw. Wireless Technol., pp. 1-9, Mar. 2015. DOI:10. 1017/S1759078715000264

\section{Introduction}

Circular polarization (CP) antennas are attractive for wireless communication applications as they can mitigate the problem caused by the misalignment between the transmitting and receiving antennas [1]. Besides, microstrip CP antennas are widely used for RFID systems and RF sensors to utilize the benefits such as low weight, low cost and easy fabrication [2]. Orthogonal feed technique and perturbation technique are two direct approaches to excite CP [3]. Several CP antenna structures based on these techniques have been reported in recent years. A microstrip antenna fed by a coplanar waveguide (CPW) has been presented in [4] where a slit is introduced to the boundary of the patch to excite CP. An arrowhead-shaped slot integrated microstrip antenna has been discussed in [5] and arrowhead-shaped slot is embedded in the first quadrant along the diagonal axis of the square patch to achieve $\mathrm{CP}$ with antenna size reduction. $\mathrm{CP}$ has been achieved in $[6,7]$ by employing the orthogonal feed technique. In [8], a technique for an array has been described to generate $\mathrm{CP}$ using linearly polarized patches creating unique angular and phase arrangements. CP array antennas that include serial fed corner truncated patches with a sequentially rotated technique [9] or a corner truncated patch array fed by a slotted waveguide [10] have been demonstrated. In this letter, a $2 \times 2 \mathrm{CP}$ array antenna designed by applying a novel technique is presented. The array consists of four linearly polarized patches fed by a feed network constructed with microstrip lines and a slot line. For ease of impedance matching, the both-sided 


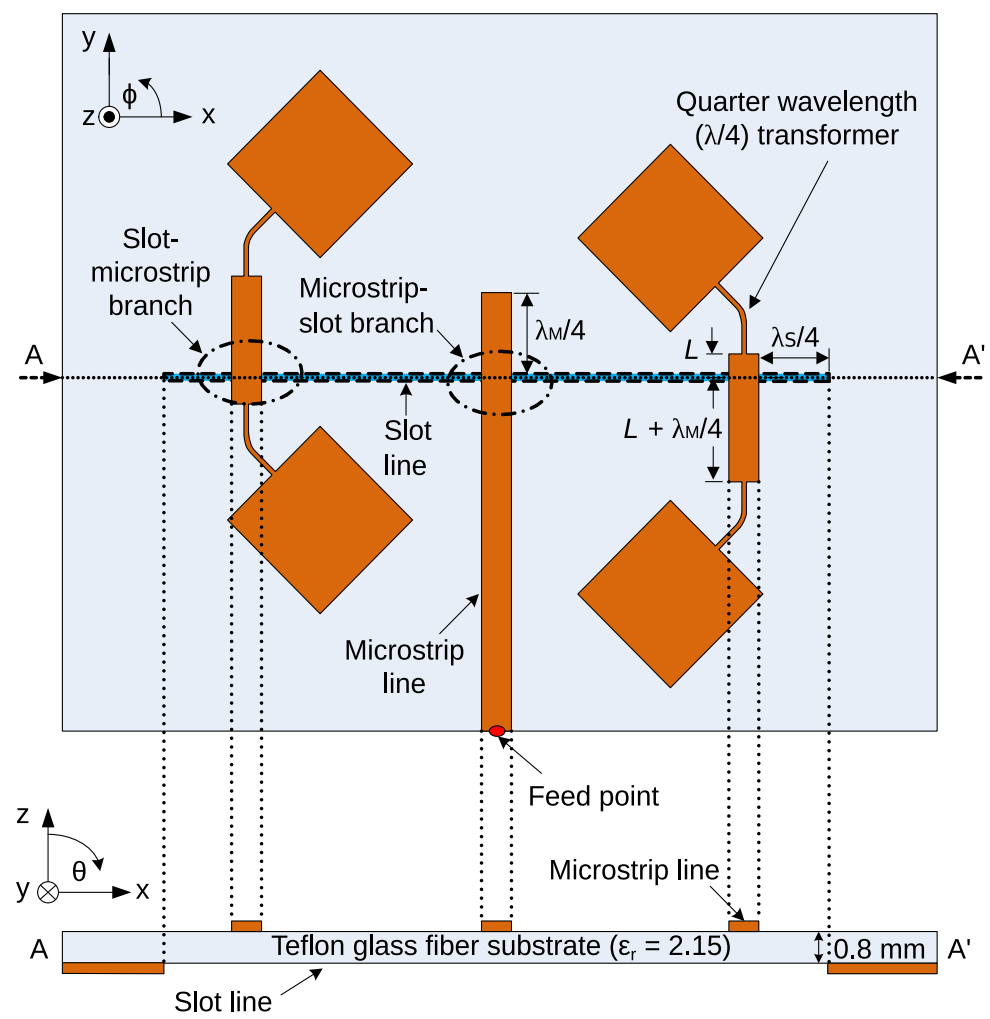

(a) Schematic layout and cross sectional view of the proposed array antenna.

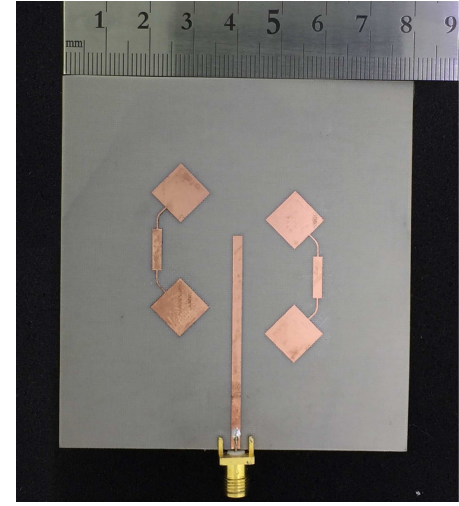

Top view

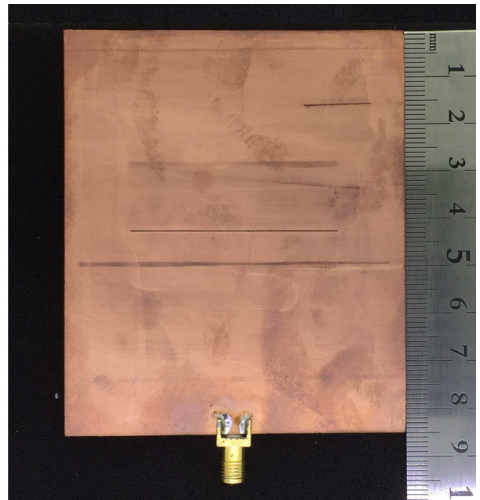

Bottom view

(b) Prototype of the proposed X-band array antenna.

Fig. 1. Proposed circular polarization array antenna.

MIC technology is used to design the array feed network. CP is achieved using inclined patches with unequal feed lines. The main benefit of this proposed antenna is that the design mechanism is much simpler than other direct approaches to excite CP. A brief description of this proposed antenna has been discussed in [11].

\section{Antenna structure}

Fig. 1(a) shows the complete schematic layout and cross sectional view of the proposed array antenna. The array consists of four linearly polarized patch elements inclined to an angle of $\pm 45^{\circ}$ with respect to the $x$ axis. Diagonal patch elements remain at the same angle $\left(+45^{\circ}\right.$ or $\left.-45^{\circ}\right)$. Moreover, two patches located at the same diagonal line are quarter wavelength ahead of the other two patches. The feed 
network of the array antenna is designed using microstrip lines and a slot line by applying the both-sided MIC technology. This feed network provides more flexible impedance matching than conventional feed networks designed using only microstrip lines [12]. In this feed network, all the microstrip lines are placed on the front side of the substrate, whereas the slot line is located on the ground surface. Two types of branch circuits are used in the feed network according to the signal transition between the microstrip lines and slot line. One of the branch circuits is a microstrip-slot branch circuit where RF signals are transferred from microstrip line to slot line. In-phase signals are obtained at slot branches due to the parallel slot branches at the microstrip-slot branch and the slot line impedance is double of the microstrip line impedance for proper impedance matching. The microstrip line extended by a quarter wavelength $\left(\lambda_{\mathrm{M}} / 4\right)$ over slot line acts as a short circuit to divert the RF signals in both slot branches properly. On the other hand, slotmicrostrip branches are formed at the two ends of the slot line where RF signals are transferred from the slot line to microstrip line. These branch circuits act as series branches and proper impedance matching can be obtained by making the microstrip line impedance half of the slot line impedance. Two microstrip branch signals of the slot-microstrip branch are anti-phase. In these branches, the extended slot line by a quarter wavelength $\left(\lambda_{\mathrm{S}} / 4\right)$ from the microstrip line acts as an open circuit. A quarter wavelength $(\lambda / 4)$ impedance transformer is used between each patch and microstrip line of the slot-microstrip branch circuit.

Fig. 1(b) illustrates the photograph of the prototype antenna for X-band. The antenna is etched on a Teflon substrate with a permittivity of 2.15 . The overall dimension of the fabricated antenna is $80 \mathrm{~mm} \times 85 \mathrm{~mm} \times 0.8 \mathrm{~mm}$.

\section{Operational mechanism of the array}

As each of the patch elements is aligned at either $+45^{\circ}$ or $-45^{\circ}$ with respect to the $x$ axis as shown in Fig. 2, Patch $\# 1$ and Patch $\# 4$ are $+45^{\circ}$ linearly polarized whereas Patch\#2 and Patch\#3 are $-45^{\circ}$ linearly polarized. As a result, two orthogonal signals are formed. Besides, Patch\#1 and Patch\#4 are ahead of Patch\#2 and Patch\#3 by a quarter wavelength maintaining the following condition:

$$
a-b=\lambda / 4
$$

where $\lambda$ is the wavelength at the design frequency. This condition creates quadrature phase shift between the two orthogonal signals. Therefore, the radiation of the proposed array antenna becomes circularly polarized.

As the signals of Patch\#1 and Patch\#4 are $90^{\circ}$ ahead of the signals of Patch\#2 and Patch\#3, the sense of CP will be left-hand CP (LHCP). The antenna can be designed to radiate right-hand CP (RHCP) by making the Patch\#2 and Patch\#3 ahead of the Patch\#1 and Patch\#4 by a quarter wavelength [1].

\section{Measured results and discussion}

Fig. 3 shows the measured and simulated results of the proposed array antenna. The antenna is designed and optimized by using FEM of Keysight Technologies' EMPro. The parametric analysis by simulation has been reported in [13]. 


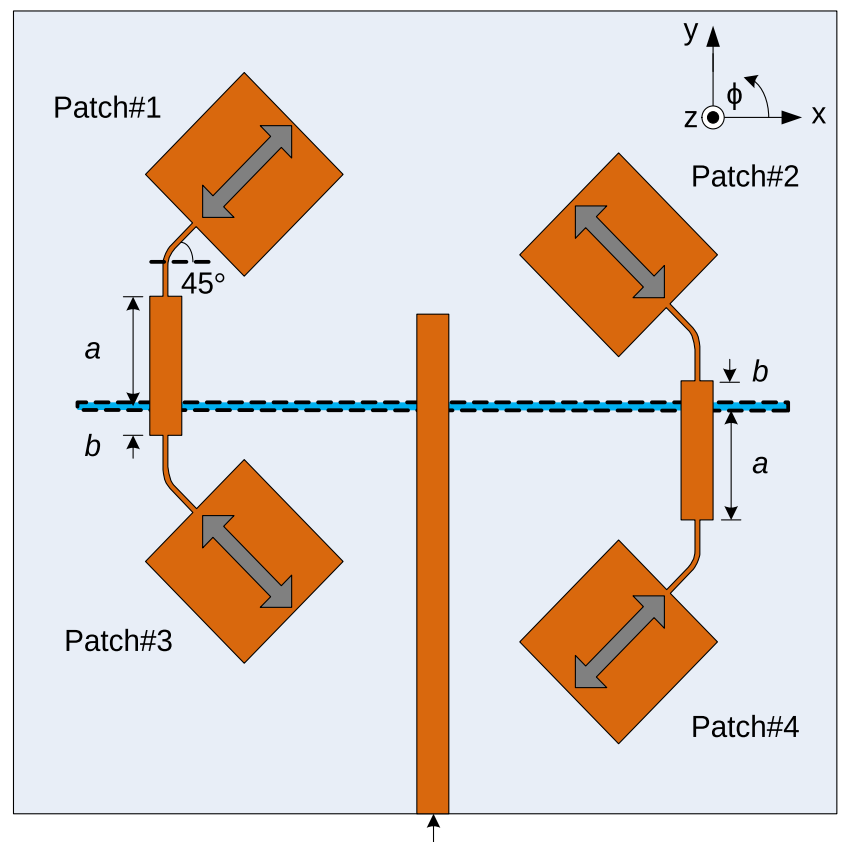

Feed point

Fig. 2. Basic behavior of the array antenna.

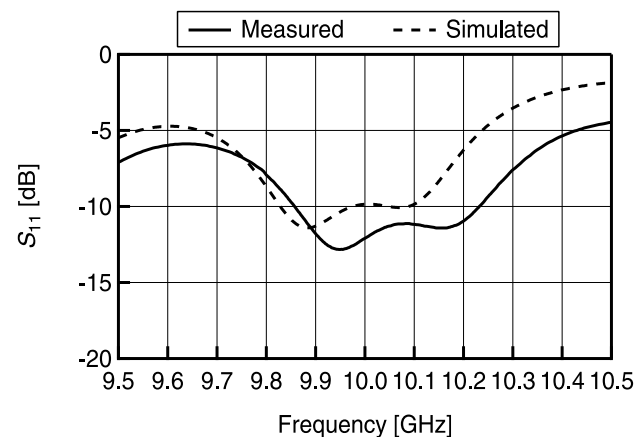

(a) Return loss

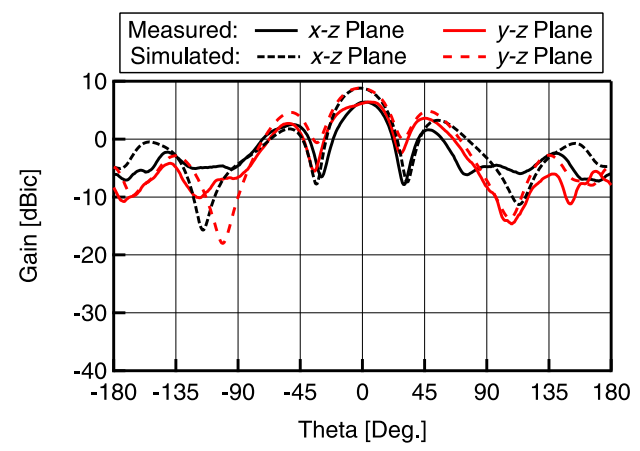

(c) Gain at $9.92 \mathrm{GHz}$

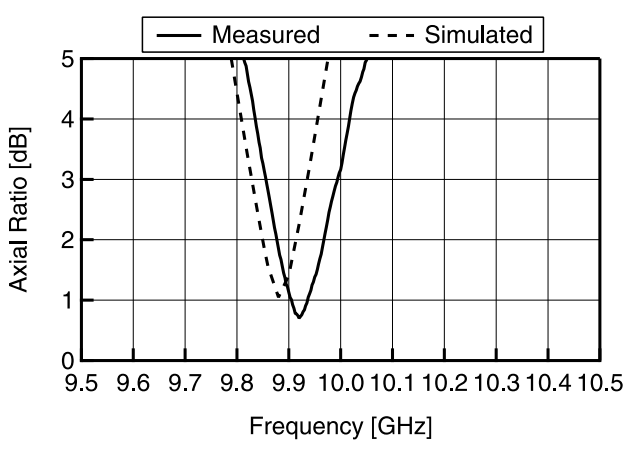

(b) Axial ratio

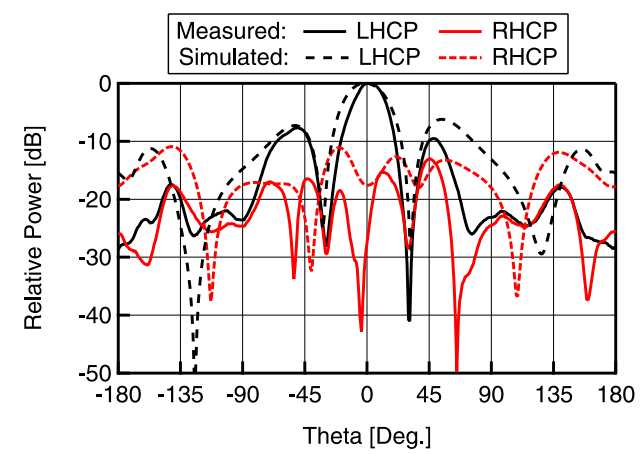

(d) Radiation pattern at $9.92 \mathrm{GHz}$ $(x-z$ plane $)$

Fig. 3. Measured and simulated results of the proposed array antenna.

Fig. 3(a) shows the return loss of the proposed antenna. The measured $S_{11}$ is better than $-10 \mathrm{~dB}$ from $9.86 \mathrm{GHz}$ to $10.23 \mathrm{GHz}$. So the return loss bandwidth of the antenna is $3.68 \%$. Fig. 3(b) presents the axial ratio of the array antenna. The measured $3-\mathrm{dB}$ axial ratio bandwidth of $1.41 \%$ is obtained with a minimum value 
of $0.70 \mathrm{~dB}$ at $9.92 \mathrm{GHz}$. The $3-\mathrm{dB}$ axial ratio beamwidths are about $23^{\circ}$ and $18^{\circ}$ in the $x-z$ and $y-z$ planes, respectively. Fig. 3(c) illustrates the gains of the antenna in the $x-z$ and $y-z$ planes. The gains of the antenna at both planes are almost the same and the maximum gain of the antenna is about $6.36 \mathrm{dBic}$. Fig. 3(d) shows the measured and simulated radiation patterns in the $x-z$ plane for $9.92 \mathrm{GHz}$. It is observed that cross polarization component is better than $-25 \mathrm{~dB}$ at $0^{\circ}$ that indicates good CP performance of the fabricated antenna. From Fig. 3(d), it is also confirmed that the CP sense of the proposed antenna is LHCP.

The design technique used in the proposed antenna to excite $\mathrm{CP}$ is very simple and straight forward. Linear polarization patches are easier to design than the $\mathrm{CP}$ patches by applying perturbation or orthogonal feed techniques. Though it takes a larger size than the single $\mathrm{CP}$ patch, but the proposed antenna is suitable for many microwave applications making a trade-off between simplicity and size.

\section{Conclusion}

In this letter, a $2 \times 2 \mathrm{CP}$ array antenna using both-sided MIC technology has been proposed by employing a new technique of exciting CP. Four linearly polarized patches inclined at $\pm 45^{\circ}$ angle are used to realize the proposed $\mathrm{CP}$ array antenna. A feed network with microstrip lines and slot line gives a simpler structure with easier impedance matching than conventional feed networks. The simple and compact structure makes the proposed antenna suitable for large scale extensible array antennas. A $3-\mathrm{dB}$ axial ratio bandwidth of $1.41 \%$ is achieved with a gain of $6.36 \mathrm{dBic}$. The proposed antenna is attractive for various types of X-band applications such as radars, RF sensors etc. 